\title{
O uso da metáfora sponsa Christi por Cipriano de Cartago como estratégia para disciplinar a virgem cristã
}

\author{
The use of the 'sponsa Christi' metaphor by Cyprian of Carthage \\ as a strategy to discipline the Christian virgin
}

Carolline da Silva Soares*

\begin{abstract}
Resumo: O bispo cartaginês Cipriano de Cartago escreveu, em 249, um tratado intitulado De habitu uirginum, no qual ele apresenta as virgens cristãs como mulheres virtuosas, mas também assinala as cautelas e as prevenções que elas devem ter em relação às tentações do mundo, que podem levá-las a abandonar a castidade e, sobretudo, a pudicitia. Em seu discurso, Cipriano faz uso de uma retórica persuasiva para tentar convencer a virgem a seguir as suas determinações e normas disciplinares. Para tanto, utiliza como estratégia, conceito cunhado por De Certeau, a metáfora sponsa Christi (esposa de Cristo), ressaltando o significado e a importância dessa expressão, de modo a justificar o comportamento exemplar, que ele espera ser adotado pela virgem cristã, baseado na modéstia e na obediência.
\end{abstract}

\begin{abstract}
The Carthaginian bishop Cyprian of Carthage wrote in 249 a treatise entitled De habitu uirginum, where he presents the Christian virgins as virtuous women, but also points out the cautions and precautions they must have in relation to the temptations of the world, which may lead them to abandon their chastity and, especially, their pudicitia. In his discourse, Cyprian uses his persuasive rhetoric to try to persuade the virgin to follow her determinations and disciplinary norms, for this reason, he uses as a strategy - a concept create by De Certeau - to use the metaphor sponsa Christi - Christ's wife - emphasizing the meaning and importance of this sentence, in order to justify the exemplary behavior that he expects to be performed by the Christian virgin, based on modesty and obedience.
\end{abstract}

\author{
Palavras-chave: \\ Cipriano de Cartago; \\ Virgem cristã; \\ Estratégia; \\ De habitu uirginum; \\ Sponsa Christi.
}

Recebido em: 01/03/2018

Aprovado em: 25/04/2018

\author{
De habitu uirginum; \\ Sponsa Christi.
}

\footnotetext{
${ }^{*}$ A autora cumpre estágio de pós-doutorado no Programa de Pós-Graduação em História da Universidade Federal do Espírito Santo (Ufes) com apoio institucional da Capes. Atualmente desenvolve pesquisas relacionadas aos estudos de gênero no cristianismo primitivo.
} 


\section{Introdução}

crença cristã é procedente de um mundo caracterizado por uma grande
diversidade cultural. Sua expansão pelo vasto território sob domínio romano
sempre foi acompanhada de um processo intenso e dinâmico de mudanças sociais caracterizadas por novos valores e atitudes comportamentais. Originário de um contexto multifacetado, o pensamento cristão foi muito diverso, de tal modo que as próprias comunidades cristãs, espalhadas pelo extenso território do Império Romano, se desenvolveram com características próprias. ${ }^{1}$

Nesse contexto de pluralidade cultural, social e religiosa entre os Padres da Igreja também não existiu uma uniformidade nos discursos em relação à mulher. Os autores da Patrística foram responsáveis por formular uma gama de discursos, apresentando diversas teorias, normas e regras direcionadas às mulheres. Em realidade, mesclaramse aspectos laudatórios com outros de caráter depreciativo. Na literatura cristã desses primeiros tempos, a imagem da mulher, como bem aponta Monique Alexandre (1990, p. 511), oscilou entre dois polos: a condenação e a exaltação. O modelo do ideal feminino aparece representado por Maria, mãe e virgem, e o protótipo contrário - o da maldade é encarnado por Eva, a primeira mulher, que caiu em tentação e levou toda a humanidade à perdição com o seu pecado (PAGELS, 1992). Assim, os eclesiásticos estabeleceram exempla que serviram de paradigma para essa distinção, como veremos adiante.

Tais discursos instituíram, de uma forma ou de outra, um arquétipo comportamental, prevalecendo as versões mais rígidas que se adaptavam aos propósitos da Igreja. Os autores cristãos estabeleceram prescrições rigorosas em relação aos comportamentos religiosos e sociais. A isso, seguiu-se um extremo rigor no tocante ao corpo, como renúncia sexual, virgindade, um único casamento, uma nova percepção corporal, a abstinência absoluta, o jejum e a flagelação do corpo (BROWN, 1990, p. 78).

Um desses escritores foi Cipriano, bispo de Cartago entre 249 e 258. De origem africana, nasceu na cidade de Cartago, capital da província da Africa Proconsularis, entre os anos de 200 e 210. Proveniente de uma família pagã, culta e de boa posição social, Cipriano, provavelmente, cumpriu todo o ciclo de estudos próprio de um filho da aristocracia romana e exerceu a profissão de professor e de advogado em Cartago. ${ }^{2}$ A sua

\footnotetext{
${ }^{1}$ Como ressaltam Chevitarese e Cornelli (2007, p. 21), não devemos trabalhar o cristianismo como sistema homogêneo, e muito menos, como religião cristalizada. O ideal é adotar a noção de cristianismos, uma vez que as comunidades cristãs "se encontravam disseminadas pela bacia do Mediterrâneo, proporcionando, em níveis locais, especificidades no ver, no sentir, no praticar essas experiências religiosas no interior dessas mesmas comunidades.

2 Sabemos muito pouco acerca da vida de Cipriano antes da sua conversão ao cristianismo. As informações das quais dispomos acerca da vida do bispo foram transmitidas de forma direta na Vita Cypriani, conservada em um número
} 
conversão ocorreu entre os anos 245 e 246. Em 249, ao morrer o bispo Donato, foi eleito episkopos da congregação cartaginesa por aclamação popular.

Diante da pluralidade de discursos eclesiásticos sobre a mulher, a nossa intenção é expor o pensamento de um desses Padres da Igreja, Cipriano de Cartago, que, em 249, escreveu um tratado intitulado De habitu uirginum, no qual dirige elogios às virgens cristãs, tratadas como mulheres virtuosas, mas também assinala as cautelas e as prevenções que elas devem ter em relação às tentações do mundo, que podem levá-las a abandonar a castidade e, sobretudo, a pudicitia, que é considerada, pelo bispo, como algo excelso e primordial para o funcionamento da comunidade cristã.

Este opúsculo elaborado por Cipriano está repleto de normas e prescrições que visam a elaborar um comportamento ideal para a virgem cristã, sobretudo aquela recémconvertida ao cristianismo e oriunda da aristocracia. Nele, o bispo ressalta, igualmente, os perigos e os castigos divinos que as virgens estão sujeitas caso não sigam o direcionamento disciplinar elaborado pelo bispo. Em seu discurso, Cipriano faz uso de uma retórica persuasiva para tentar convencer a virgem a seguir as suas determinações, sendo uma das estratégias utilizadas pelo bispo a de denominá-la como sponsa Christi (esposa de Cristo), ressaltando o significado e a importância dessa sentença para as virgens, para Cristo e para toda a Igreja.

De tal modo, temos a intenção de evidenciar o discurso de Cipriano contido no De habitu uirginum e o uso que ele faz da metáfora sponsa Christi para disciplinar o corpo da virgem e moldar o seu comportamento. No entanto, antes de adentrarmos em nosso objetivo principal - a análise da metáfora supracitada como estratégia de convencimento das virgens -, não podemos deixar de ressaltar o discurso e, consequentemente, o ideal de mulher e de virgindade difundido na sociedade greco-romana imperial e, em especial, no cristianismo primitivo.

\section{Entre a virgindade e a procriação: $o$ ideal de mulher na sociedade greco-romana}

Na sociedade greco-romana imperial, assim como no cristianismo primitivo, não podemos dizer que vigorava um discurso único e homogêneo sobre o ideal de mulher.

\footnotetext{
significativo de manuscritos, que Jerônimo atribui a Pôncio, diácono de Cartago e biógrafo de Cipriano. Outras fontes que foram conservadas são as atas proconsulares de Cipriano, comumente conhecidas como Passio Cypriani, que descrevem detalhadamente o processo de Cipriano ante o tribunal proconsular em Cartago, nos tempos de Valeriano, e que culmina com o martírio do bispo, em 258. Dispomos também das obras escritas pelo próprio Cipriano, sobretudo as suas Epistulae. No entanto, em relação ao período anterior à sua conversão, Cipriano se mostra reticente. Para reconstituir o seu passado pagão devemos recorrer aos autores posteriores, principalmente os dos séculos IV e V, como, por exemplo, Lactâncio, na Diuinae institutiones; Agostinho, no tratado De doctrina Christiana e no sermão In Natali Cypriani; Eusébio de Cesareia, na Historia ecclesiastica; além de Jerônimo, como mencionado acima.
} 
No entanto, é importante ressaltarmos a concepção que vigorava à época, pois é esta que as fontes documentais que chegaram até nós - escritas, sobretudo, por homens - nos mostram e que evidenciam o que era esperado de uma mulher e o seu papel na sociedade. Martínez López (1994, p. 173) enfatiza essa afirmação ao dizer que "o modelo ideal de mulher foi estabelecido por um coletivo masculino de cidadãos que determinou, de forma oficial, a razão de ser e a função de cada sexo na sociedade".

A função primordial das mulheres, grosso modo, no mundo greco-romano, estava relacionada à capacidade fértil do seu corpo, ou seja, a comunidade esperava que ela fosse capaz de procriar e, assim, perpetuar a família, elemento basilar para a continuidade da sociedade e do Estado. ${ }^{3}$ Assim, aqueles que tinham a prerrogativa e o reconhecimento oficial, ou seja, os homens, os cidadãos que entendiam do regimento da coisa pública, buscaram sempre controlar essa potencialidade feminina - a capacidade de procriar por meio da criação de normas legais, rituais religiosos e discursos científicos. De tal modo, mesmo que a vida das mulheres fosse regida pela principal função que deveriam desempenhar na sociedade, a procriação, o controle do seu corpo, no plano teórico e legal, não Ihes pertencia.

Dessa maneira, enquanto os homens eram estimados por sua capacidade em integrar-se na cidade e participar, cada um segundo sua categoria, dos assuntos públicos, as mulheres eram valorizadas pelo sucesso no cumprimento das funções que Ihes correspondiam segundo a "sua natureza", sobretudo as que estavam relacionadas à fecundidade e à procriação. Contrariamente às mulheres, os homens não eram designados pelos momentos de sua história individual - matrimônio, paternidade, viuvez, etc. -, mas por aqueles que determinavam suas capacidades para intervir na vida cívica, ou seja, as mudanças nos seus ciclos de vida eram fundamentalmente políticas, enquanto os ciclos de vida das mulheres tinham um caráter pessoal e eram denominados por sua condição física em relação à maternidade (MARTíNEZ LÓPEZ, 1994, p. 170-171). Apesar da concepção tradicional atribuir os âmbitos público ao homem e privado à mulher, percebemos que a vida pessoal e privada das mulheres se via invadida pelo público e seus comportamentos privados tinham uma projeção na vida da comunidade, ideia que corrobora mais uma vez a afirmação de que elas não possuíam o controle sobre os seus corpos.

As virtudes essenciais e mais apreciadas nas mulheres eram a virgindade e a castidade. Uma das etapas da vida das mulheres, no mundo greco-romano, era

\footnotetext{
${ }^{3}$ Era na manutenção e na reprodução da família que se radicava a função social primordial das mulheres, pois a família era um elemento chave na articulação do sistema social, econômico e político romano, e o Estado dedicou grandes esforços ao longo da sua história para protegê-la e fortalecê-la (MARTíNEZ LÓPEZ, 1994, p. 172).
} 
determinada pela virgindade, que funcionava como uma antessala para a fecundidade. A categoria "virgens" compreendia, então, todas as jovens que se encontravam na idade para contrair matrimônio e se associava à continuidade do sistema social e familiar. A infância e a puberdade das mulheres estavam determinadas pela virgindade, uma etapa em que as mulheres mantinham intactas todas as suas forças, sua potência para a futura fecundidade (GRIMAL, 1981). ${ }^{4}$ De tal modo, as jovens solteiras e, também, as mulheres casadas, eram estimadas no âmbito familiar e social pela adequada reprodução dos papéis de gênero que Ihes eram conferidos. ${ }^{5}$

As mulheres eram virgens até o matrimônio e, uma vez casadas, eram definidas por seu estado civil, uxor, ou por sua maternidade e status, matrona ou materfamilias. De tal modo, o que interessava à cidade, em relação às mulheres, era a sua aptidão física, legalizada pelo matrimônio, para a procriação, ou seja, para a reprodução do corpo de cidadãos e, em função disso, se estabeleciam suas idades e ciclos vitais: capacidade para procriar, etapa de fecundidade e etapa de infertilidade. Por isso, a vida das mulheres se dividia em dois grandes momentos, antes e depois do matrimônio (MARTíNEZ LÓPEZ, 1994, p. 171).

Por isso, a imagem da mulher costuma aparecer cindida em dois tipos: a mulher casta e aquela que não é. A virgindade nas donzelas e a pudicitia nas casadas eram consideradas elementos chave para assegurar o bem-estar da casa, da comunidade ou para estabelecer a relação com os deuses quando se havia produzido uma desgraça. ${ }^{6}$ Em relação à mulher casada, a sua pudicitia não se reduzia à fidelidade ao marido, mas também à sua modéstia nos vestidos, na palavra e no conjunto de seu comportamento social (MARTÍNEZ LÓPEZ, 1994, p. 173-174).

\footnotetext{
${ }^{4}$ Pierre Grimal (1981) analisa as diversas aplicações da palavra virgo na literatura latina e afirma que esta denominação geralmente é aplicada a uma jovem em suas potencialidades de mulher ainda não realizadas ou apenas expressadas. Por isso, as virgens eram uma virtualidade de fecundidade, uma força disponível para maternidades futuras.

${ }^{5}$ As sociedades mediterrâneas antigas chegaram a dar à castidade um conteúdo quase mágico, em estreita união com a fecundidade e a prosperidade das comunidades. Esta relação, aparentemente contraditória, está presente em numerosos relatos e lendas que falam de sacrifícios de virgens pelo bem da comunidade, como se seu sangue possuísse um poder de fecundidade. Estes relatos de virgens sacrificadas são abundantes na mitologia grega. Entre eles, o mais famoso é o de Ifigênia, a primeira sacerdotisa do culto a Ártemis, que envolvia ritos sangrentos (GRIMAL, 1981, p. 206212), numerosos rituais de caráter cívico-religioso, que incluíam coros de meninas e jovens em procissão, consagração de virgens como sacerdotisas na condição de mediadoras entre os mortais e os deuses (ZAIDMAN, 1991).

${ }^{6} \mathrm{~A}$ mulher não casta, ou seja, aquela que não aceitava por completo as normas estabelecidas para o seu sexo, quase sempre aparece como causadora de algum mal, de alguma desgraça para a comunidade. Há diversos exemplos na Antiguidade, desde Eva até numerosas referências oferecidas pelos gregos e romanos: Pandora libertou os vícios e as calamidades do mundo; Aristóteles culpou as mulheres espartanas pela ruína da cidade; Teopompo e Lívio insistiram no fato de que as formas de vida das mulheres etruscas foram um fator decisivo na degeneração da Etrúria; Juvenal falou da corrupção das mulheres romanas como um sintoma de enfermidade nas sociedades, etc. Pode-se, portanto, afirmar que, nas sociedades antigas, foi uma constante unir a virtude e a castidade das mulheres com o bem-estar dos povos e dos Estados (MARTÍNEZ LÓPEZ, 1994, p. 174; POMEROY, 1999, p. 234).
} 
Diferentemente da ideia que veremos florescer no cristianismo, na sociedade greco-romana imperial a virgindade nunca foi considerada um valor desejável para as mulheres ao longo de sua vida. A etapa central e a mais importante das mulheres era a da fertilidade, o momento da reprodução. A virgindade era somente a etapa prévia que deveria ser cuidada e resguardada para assim, mais tarde, obter-se os melhores frutos. ${ }^{7}$ De tal forma, nos discursos políticos, religiosos e científicos da época, fica evidente que a trajetória ideal das mulheres é em direção ao matrimônio. ${ }^{8}$

$\mathrm{Na}$ sociedade greco-romana imperial, o lugar ocupado pela mulher era de inferioridade em relação ao homem, ou seja, à mulher foi associada uma debilidade natural que afetava o seu plano físico, intelectual e moral (TORRES, 2013, p. 244). ${ }^{9}$ Tal característica foi apropriada, também, pelos Padres da Igreja, uma vez que, inseridos nesta sociedade, eram herdeiros desse tipo de pensamento. Assim, a diferenciação entre os sexos e a identificação de cada um deles com os conceitos do bem e da virtude, no caso do homem, e do mal e do vício, no caso da mulher, eram tendências que se encontravam presentes na literatura clássica greco-romana e que se inseriram no Antigo Testamento ${ }^{10}$ e nas epístolas de Paulo. ${ }^{11}$

\footnotetext{
${ }^{7}$ Eram as jovens virgens que asseguravam a continuidade e a pureza da família, na medida em que não haviam conhecido, antes de seu matrimônio, relação sexual alguma. Os romanos acreditavam que toda relação sexual marcava o sangue da mulher e ela transmitia a particularidade do seu amante anterior - ou amantes - à sua progenitura (MARTÍNEZ LÓPEZ, 1994, p. 173).

${ }^{8}$ Galeno afirma que as jovens que não se casam quando chega a época do matrimônio experimentam, à primeira aparição das regras (menarca), acidentes a que antes não estavam expostas: ao não encontrar o orifício de saída, o sangue volta ao ventre (à matriz) e o diafragma se projeta ao coração, etc. E recomenda às jovens que logo se casem, pois a gravidez é a cura para tais males. Vemos, assim, que a justificativa "científica" corrobora o matrimônio das jovens antes da primeira menstruação e a fertilidade como razão fundamental de uma mulher. Para uma análise do discurso de Galeno, cf. Rousselle (1984).

${ }^{9}$ Segundo Seraphin (2009, p. 3), "na mesma perspectiva de Hipócrates, Galeno (século II d.C), em sua obra De usu partium corporis humani, afirma que as mulheres são menos perfeitas que os homens, por uma razão principal, pois são mais frias. Argumenta que, entre os animais, o quente é mais ativo. Sendo assim, os animais frios seriam menos perfeitos. Na humanidade, segundo Galeno, os homens são mais perfeitos que as mulheres, e a razão para esta perfeição está no fato de que são mais quentes".

${ }^{10}$ É em Provérbios, sobretudo, que iremos encontrar as duas imagens, positiva e negativa, sobre a mulher.

${ }^{11}$ Enquanto que em Gálatas 3, 28; I Coríntios 7, 3-5 e I Timóteo 2,15 Paulo fala a favor da igualdade dos sexos e dos esposos, em contrapartida, em / Coríntios 11, 3-5 e em / Timóteo 2, 11-14, diz que a mulher deve cobrir a sua cabeça para orar e a proíbe de ensinar. Essa dupla avaliação de Paulo sobre a mulher gerou uma abundante produção bibliográfica resultante das discussões entre os historiadores que consideram o apóstolo um feminista e aqueles que vão contra tal ideia. Diante disso, alguns estudiosos consideram as cartas de Paulo a Tito, a Timóteo e a Efésios como inautênticas, pois são as que reúnem as considerações mais contrárias às mulheres. Para maiores informações sobre esse assunto, cf. Pagels (1974), Scroggs (1972) e Walker (1975).
} 


\section{O ideal feminino traçado pelo Padres da Igreja}

Como contraponto ao modelo feminino pagão encarnado pela matrona romana, que acatava as regras da tradição - o mos maiorum -, os cristãos elaboraram outro ideal de mulher, adaptado aos seus valores morais e distinto dos princípios pagãos. Para além dessa diferenciação, o fato é que ambos os arquétipos femininos possuíam muitos pontos em comum, sobretudo em relação à boa reputação e às virtudes que a mulher deveria possuir, como, por exemplo, honestidade, docilidade, amabilidade, piedade, recato no vestir, simplicidade nos adereços, castidade, fidelidade, entre outros. De tal modo, qualquer mulher cristã que reunisse em sua pessoa esse conjunto de predicados constituiria, igualmente, o ideal feminino para os moralistas cristãos (TORRES, 2013, p. 245).

Esse modelo, no entanto, mostrava-se um tanto ou quanto genérico. Foi necessário, então, adaptar o ideal de mulher às diferentes exigências culturais e sociais da época. Os discursos cristãos partiram da ideia preconcebida da inferioridade feminina em relação ao homem, porém essa condição poderia ser superada por meio da ascese, que equipararia a mulher ao homem, convertendo-a em mulier virilis (ASPEGREN, 1990, p. 33-48). ${ }^{12}$

Desde o princípio, a mulher foi sensível à mensagem evangélica, por meio da qual tomou consciência de sua igualdade com o homem, de sua condição de pessoa que livremente podia escolher um modelo de vida, à margem dos costumes estabelecidos, que ofereciam como alternativa um matrimônio, em sua maioria dos casos, não escolhido; relações sexuais não desejadas, mas de cumprimento obrigatório; o adultério e o repúdio masculino; e, por último, se ficasse viúva, uma situação de indigência e desproteção social, se não tivesse patrimônio familiar (HIDALGO DE LA VEGA, 1993, p. 232-233). Diante dessa situação, a abstinência sexual - castidade - se manifestava como uma nova forma de autonomia na vida da mulher, ainda que tivesse que renunciar aos desejos e necessidades próprios da natureza humana.

No entanto, a escolha pela conversão cristã e pela castidade foi vista pela sociedade greco-romana como uma afronta aos valores da cidade antiga, pois geravam um conflito familiar e paterno, já que essa atitude foi entendida como um ato de desobediência à autoridade do pater famílias, questionando-se, assim, a ordem patriarcal (FIORENZA,

\footnotetext{
${ }^{12}$ Essa revalorização da mulher estava em consonância com o caráter libertador da mensagem evangélica, graças à qual se produziria uma equiparação de todos os homens, independentemente da condição social, de gênero e raça, como esclarece a passagem de Gálatas 3, 28: "Não há judeu nem grego, não há escravo nem livre, não há homem nem mulher; pois todos vós sois um só em Cristo Jesus". De acordo com Torres (2013, p. 246), esta passagem de Paulo diz respeito à soteriologia cristã, referindo-se à igualdade de todos os cristãos ante a salvação.
} 
1994, p. 265). ${ }^{13}$ Ademais, para a sociedade, ao optar pela castidade, a mulher estaria desprezando o matrimônio e colocando em risco a raça humana. ${ }^{14}$

Diante do exposto, os discursos patrísticos, de uma forma ou de outra, instituíram um arquétipo comportamental sobre as mulheres, prevalecendo as versões mais rígidas que se adaptavam aos propósitos da Igreja. Assim, a conversão ao cristianismo acarretava uma série de mudanças na vida do indivíduo, sobretudo para as mulheres e, ainda mais, para as virgens. ${ }^{15}$ Ela trazia consigo a necessidade de alteração de algumas atitudes em relação ao corpo, a si próprio, aos outros, à natureza e a Deus, com um novo sentido de obrigação política e social. Em relação ao lugar ocupado pelas mulheres, sobretudo pelas virgens, isso foi bem marcado dentro dos círculos cristãos. A abstinência sexual teve um grande destaque, pois acreditava-se que tal comportamento tornava o corpo humano um veículo mais propício para acolher a inspiração divina (BROWN, 1990).

\section{Cipriano e a elaboração do De habitu uirginum}

Um dos aspectos dos estudos sobre o cristianismo primitivo nos últimos anos tem destacado a importância das mulheres em termos de cuidado pastoral oferecido pelos clérigos, especialmente os bispos, ao invés de simplesmente destacar as atitudes em termos teológicos. As virgens de Cartago foram um dos quatro grupos de mulheres que ganharam a atenção de Cipriano.

No contexto de construção do discurso de Cipriano sobre as virgens, ressaltamos que a atividade literária do bispo foi provocada por circunstâncias particulares e respondeu a propósitos práticos (CAMPOS, 1964). De acordo com Dell'Osso (2006, p. 19), o trabalho de Cipriano não é resultado da reflexão de um escolástico ou de um teólogo, mas a ação de um líder eclesiástico, bispo e pastor. A virgindade, para Cipriano, não foi simplesmente uma questão teológica, mas, sobretudo, um problema pastoral, demonstrando que esperava um maior grau de comprometimento comportamental das virgens do que de qualquer outro grupo dentro da Igreja (DUNN, 2003, p. 2-3). Seus tratados e cartas foram amplamente distribuídos e apreciados nas comunidades ocidentais e dentre os escritos

\footnotetext{
${ }^{13}$ O Estado romano, como principal responsável pela sociedade, exercia uma pressão sobre as mulheres - sobretudo aquelas dos setores dominantes - para que seus corpos fossem usados com fins reprodutivos e com o objetivo de participarem do projeto coletivo imposto pela própria sociedade. Nesse contexto, o papel da mulher seria de mera espectadora, recaindo sobre ela a responsabilidade primordial da continuidade e da coesão da organização social, materializada no matrimônio, reprodução e cuidado dos filhos (HIDALGO DE LA VEGA, 1993, p. 235).

${ }^{14} \mathrm{Um}$ dos maiores problemas das sociedades antigas e, nesse caso, da greco-romana, está relacionado à questão da reprodução da espécie humana, dado o alto índice de mortalidade e a baixa expectativa de vida, que variava entre os 20 e 30 anos de idade (HOPKINS, 1966).

${ }^{15}$ Cf. Soares (2014).
} 
caracterizados como disciplinares dentro do corpus Cypriani se destaca o De habitu uirginum (CAMPOS, 1964, p. 35).

Ao crermos em Viciano (2006), Cipriano deixou-se influenciar por dois tratados de Tertuliano, o De uirginibus velandis e o De cultu feminarum, e, igualmente, pela antropologia greco-romana, judaica e cristã, segundo a qual a mulher era um ser humano inferior, como explicamos anteriormente. Já Keenan (1958, p. 29) destaca a dependência de Cipriano diante desses dois trabalhos de Tertuliano, citados acima, mas também do De pudicitia e do De ehxortatione castitatis.

Cipriano dirigiu seu tratado às mulheres ricas da comunidade cartaginesa que, apesar de terem optado pela virgindade, não estavam dispostas a mudar o seu estilo de vida. ${ }^{16}$ O bispo tenta claramente convencê-las a mudar, uma vez que elas não demonstravam um comportamento compatível com o status de virgem cristã. Ele, então, recomenda às virgens não portar vestidos ostentosos, não utilizar enfeites na face, adornos e tintura nos cabelos. Aconselha-as, ademais, a não estarem presentes nas festividades e nos espaços da cidade antiga. ${ }^{17}$

Ao que parece, a comunidade cristã da capital africana possuía um grupo de mulheres que pertenciam a grupos sociais mais elevados e que dispunham de recursos para incluir objetos caros em sua indumentária, como joias refinadas, tecidos elegantes e pérolas. Provavelmente, essas mulheres da comunidade cartaginesa, a quem Cipriano dirige o seu discurso, pertenciam à ordem senatorial e à ordem dos decuriões (WATSON, 1920-1921, p. 365).

O trabalho do bispo era direcionado a tentar persuadir as virgens por meio do sermão, esclarecendo a necessidade de aceitar a disciplina eclesiástica e de basear o seu comportamento em elementos de referência como a simplicidade, a humildade, a obediência e a abstinência sexual. E uma das maneiras de tentar convencê-las foi a utilização da metáfora sponsa Christi (DUNN, 2005a, p. 205; DUNN, 2005b, p. 295).

\section{O uso da metáfora sponsa christi e a elaboração de uma teologia sobre a virgindade}

Antes de Cipriano, Tertuliano foi o primeiro autor cristão a utilizar a metáfora do casamento como um elemento de união da virgem com Cristo, uma vez que, unidos em casamento, ela se tornava a sponsa Christi. No entanto, nas obras tertulianas ainda não é possível encontrar, como menciona Mentxaca (2013, p. 11), uma teologia elaborada

\footnotetext{
${ }^{16}$ Cf. Soares (2013).

${ }^{17}$ Cf. Soares (2017).
} 
acerca da virgindade. Com a abertura desse precedente e com o notável crescimento e expansão da virgindade na sociedade cristã da época, Cipriano foi o primeiro que tratou as virgens como uma categoria separada, e superior, dentro da Igreja.

No desenvolvimento da teologia da virgindade, a forma de consagração das virgens transpôs o comportamento característico esperado das esposas, ou seja, o comportamento que existia entre o marido e a mulher num casamento, aplicando-o à relação da virgem com Cristo (MENTXACA, 2013, p. 15). Segundo Vizmanos (2009, p. 159-161), o sinal que denotava que a virgem era a esposa de Cristo era o véu que lhe era imposto no dia da consagração. É importante ressaltar, no entanto, que, em meados do século III, a decisão em permanecer virgem não era acompanhada por um ato público de consagração ou de uma pública demonstração do voto de castidade. É somente no século IV que vislumbraremos indícios de uma consagração das virgens e a institucionalização da ordo uirginum. A categoria das virgens, então, passará a ser regulada por regras de comportamento de acordo com as disposições religiosas, mas ainda sob formas muito diversas, variando entre a vida isolada no mosteiro e a na casa da família (RAMIS, 1990).

A metáfora da virgem como esposa de Cristo desempenhou um papel muito importante na construção da teologia da virgindade no discurso de Cipriano (MENTXACA, 2010). O bispo qualifica as virgens como esposas de Cristo. No entanto, como dito acima, essa metáfora não é original de Cipriano, pois foi Tertuliano o primeiro escritor cristão a utilizá-la, ao afirmar que a virgem estava unida em casamento com Cristo e, por isso, era a sponsa Christi. ${ }^{18}$

Cipriano emprega essa expressão com o desejo de modificar o modo de vida das virgens cristãs, introduzindo um padrão de comportamento considerado discreto, recatado e humilde. Destacamos o fato de que Cipriano utiliza a metáfora da sponsa Christi na construção do seu discurso como uma estratégia, nos moldes traçados por Michel de Certeau (2009), com a finalidade de persuadir e convencer as virgens a seguir as normas prescritas. De Certeau, ao analisar as práticas das pessoas comuns e o comportamento de diversos grupos no cotidiano, enfatiza a ação ativa e criativa desses grupos e dos indivíduos. Assim, o autor entende o cotidiano a partir das táticas que os indivíduos criam ou adotam em seu dia a dia como forma de resistência a uma série de códigos estratégias - estabelecidos pelos agentes do poder.

Percebemos, no discurso disciplinador de Cipriano, uma série de códigos de conduta constantemente reforçados pelo bispo, que utiliza, entre diversas expressões retóricas e metafóricas, a expressão sponsa Christi para tentar convencer a virgem a se

\footnotetext{
${ }^{18}$ Sobre o uso dessa expressão pelos Padres da Igreja, cf. Vizmanos (2009).
} 
enquadrar num tipo de comportamento almejado por ele. Ele profere o seguinte: "[...] vosso senhor e cabeça é Cristo, assim como vosso esposo, com quem deve compartir vossa sorte e condição" (Cipriano, De habitu uirginum, 22).

Com o uso dessa metáfora, Cipriano evidencia, então, a estratégia de delimitar o modo como uma virgem cristã deveria agir e se comportar. Contrariamente ao que fora imposto pelo bispo como sua estratégia para manter a ordem, para organizar a cidade multicultural, que ele julgava caótica, percebemos, igualmente, as táticas das virgens, que as desviam para fins próprios. Percebemos, de tal maneira, que parte considerável das virgens não fora afetada pelas deliberações do bispo, uma vez que algumas delas ainda continuava, após o batismo, a manterem relações de sociabilidade com os adeptos de outras crenças no dia-a-dia, a frequentarem os espaços da cidade antiga condenados por Cipriano e, sobretudo, a manterem um tipo de conduta que não era apropriado a uma virgem, com o uso de joias, maquiagem e vestimentas luxuosas.

O bispo intenta disciplinar as virgens cristãs enquanto avisa sobre as precauções que devem ter em relação às muitas tentações que encontrarão em sua vida diária. Em relação a tais tentações mundanas, Cipriano (De hab. uirg., 7) menciona a ostentação de bens e diz: "Existem algumas ricas e opulentas, pela abundância de seus bens, que ostentam as suas riquezas e afirmam que devem fazer uso delas", contrariando a ideia apregoada pelo bispo de que "somente é rica de verdade aquela que é rica com Deus e que é opulenta a que é com Cristo, [pois] os verdadeiros bens são os espirituais, os divinos, os celestes, que nos levam a Deus" (Cip., De hab. uirg., 7).

Acerca dos penteados que as virgens portam e que chamam a atenção, ele profere:

Se tu te penteias luxuosamente, se andas em público com ostentação, se seduzes os olhares dos jovens, se atrais os suspiros dos adolescentes, se nutres a paixão, se inflamas os incentivos do desejo, de modo que embora não te percas, leves outros à perdição, oferecendo-te como gládio e como veneno aos que te comtemplam, não te podes desculpar como sendo casta e pudica em espírito, [pois] o luxo inconveniente e o ornato impudico acusam-te de [falsidade] (Cip., De hab. uirg., 9).

Em seu opúsculo, Cipriano (De hab. uirg., 5) questiona as virgens da seguinte forma: "Se a continência segue o Cristo e a virgindade é destinada ao reino de Deus, o que elas têm a ver com os cuidados mundanos e os ornamentos pelos quais procuram agradar aos homens e ofender a Deus?". Dessa maneira, podemos ver que outro motivo para a admoestação de Cipriano é a ostentação de roupas e adornos. O bispo afirma que "o luxo de ornamentos e vestes e a sedução das formas só convêm às prostitutas e às mulheres impudicas, e ordinariamente não há vestes mais preciosas do que as daquelas cujo pudor 
é vil" (Cip., De hab. uirg., 12). Em outro trecho, reafirma sua censura ao uso de joias, ao mencionar que:

Deus não fez as ovelhas escarlates ou purpúreas, nem ensinou a tingir e colorir a Iã com o suco de ervas ou de moluscos. Não ensinou a fabricar joias encrustando no ouro pedras preciosas ou pérolas numa sucessão compacta e encadeada por numerosas ligações. Para ocultares o pescoço por ele criado, cobrir o que Deus fez no homem, ao contrário, ostenta o que o diabo inventou (Cip., De hab. uirg., 14).

Fazer uso de maquiagem e de coloração nos cabelos também são práticas reprovadas por Cipriano (De hab. uirg., 14), que profere:

Foram os anjos caídos e os apóstatas que trouxeram, astutamente, todos esses artifícios, quando, precipitados na imundície terrena, perderam a virtude celeste. Eles ensinaram a pintar os olhos contornando-os de preto, a colorir as faces com falso rubor, a mudar o cabelo com coloridos falsos e a desfigurar o natural do rosto e da cabeça com enfeites artificiais.

As virgens que procedem dessa forma, ou seja, que possuem o costume de se adulterarem com a utilização de roupas, pinturas, joias e maquiagem levam Cipriano (De hab. uirg., 17) a questioná-las da seguinte forma: "Tu que assim procedes, não receias que, quando chegar o dia da ressurreição, o teu criador não te reconheça? Que, repreendendote com energia de censor e juiz, diga: 'Isto não é minha obra, nem é nossa imagem'"? ${ }^{19}$

A ideia de que as virgens devem ser tímidas, modestas, recatadas e rejeitar os adornos é repetida em várias passagens do tratado. Ademais, assim como a mulher casada que sempre busca agradar o marido, o bispo afirma que a virgem tudo tem que fazer para agradar a Cristo, uma vez que qualquer adulteração da criação natural de Deus seria considerada uma corrupção. ${ }^{20}$ Segundo o bispo, Deus não perdoaria o fato de a virgem se pintar, decorar e enfeitar, por isso podemos considerar que as declarações de Cipriano caracterizam-se como uma avaliação extremamente negativa da mulher cristã

\footnotetext{
19 Pensamos que seguir uma conduta de simplicidade em relação à vestimenta e à ausência de adornos seria algo difícil para as mulheres abonadas e oriundas da aristocracia. A variedade de tecidos era enorme (lã, algodão, linho, seda e seus derivados) e havia uma diversidade de cores, aliadas aos bordados e aos ornamentos incrementados por joias, como colares, pulseiras, brincos e anéis, em ouro, prata ou pérolas. Tudo isso fazia parte da indumentária feminina. A arte dos penteados também ocupava um bom tempo das mulheres. Elas se esmeravam em ondular os cabelos, cuidadosamente, com acessórios: diademas de tecido ou de metal precioso, ornatos de pérolas e gemas, pentes de marfim, alfinetes de bronze. Recorria-se, ainda, às perucas e às tinturas. Além de todos esses adereços, a elegância feminina era finalizada com maquiagem, perfumes e unguentos líquidos (GRIMAL, 1995, p. 96). Para maiores informações, cf. Robert (1995).

${ }^{20}$ Apesar dessa comparação, Cipriano enfatiza que a mulher casada também tem que conservar o recato, a retidão e a humildade, e que a virgem, nesse sentido, deve ser um exemplo de modéstia a ser seguido pelas outras mulheres cristãs. De tal forma, Mentxaca (2013, p. 20) menciona que as mulheres não poderiam reivindicar a necessidade de agradar seus maridos para justificar o modo como se comportam na sociedade, pois elas têm que ser favoráveis a Cristo e ele não gosta de ornamentação, falta de modéstia e trajes extravagantes.
} 
que opta por fazê-lo. Pelo uso de cosméticos, Cipriano é implacável ao chamá-la de impudica, incesta e adultera.

Como exposto acima, Cipriano assinala, no De habitu uirginum, que as virgens cristãs de Cartago não deixaram de lado o luxo e a vaidade das vestimentas, da maquiagem e dos penteados. Ademais, ao crermos nas admoestações do bispo, elas também não abandonaram, em sua totalidade, as festividades e os usos dos espaços da cidade antiga, como as bodas, os banquetes, os teatros, os anfiteatros, as termas, as sinagogas, entre outros. Tais espaços eram, para Cipriano, lugares perigosos, pecaminosos, poluidores, que deveriam ser evitados a todo custo pelas virgens. Uma das proibições mais reiteradas que Cipriano traça em sua obra diz respeito ao hábito das virgens em frequentar as termae, os banhos públicos da cidade. ${ }^{21}$ Cipriano (De hab. uirg., 19) pronuncia o seguinte sobre tal prática:

E o que se dirá das que vão aos banhos em promiscuidade, e prostituem a castidade ante os olhares curiosos e lascivos? Quando ali veem os homens nus e são vistas por eles com falta de vergonha, por acaso não encorajam e provocam a paixão dos presentes para sua própria vergonha e desgraça? [...] Mais te suja que te lava este banho, não te limpa os membros, mas mancha-os. Você poderá não ver as coisas com olhos desonestos, mas os outros assim olharão a ti.

O bispo chama a atenção daquelas virgens que se exibiam nas termae, ao dizer:22

Faz do banho um espetáculo mais vergonhoso que o teatro aonde vai. Lá todo recato está excluído; lá se desprende, enquanto a roupa protege, de sua dignidade e pudor, o corpo, se põem descobertos os membros virginais para ser objeto de olhares e curiosidade (Cip., De hab. uirg., 19).

Cipriano, ao que tudo indica, tinha conhecimento da existência do banho misto nas thermae deCartago, eseus argumentossugerem queesteera habitual ebemaceito nacidade, o que o faz levantar uma grande polêmica acerca desta prática, dirigindo-se às virgens cristãs (WARD, 1992, p. 144). ${ }^{23}$

A preleção de Cipriano estava em consonância com o discurso masculino característico do cristianismo - como mencionado anteriormente -, ou seja, um discurso que tentava impor às virgens uma série de admoestações, regras e normas a serem

\footnotetext{
${ }^{21}$ Para maiores informações acerca dos espaços da cidade greco-romana que Cipriano proibiu os cristãos, de forma geral, de transitarem, cf. Soares (2017).

22 Graça (2004, p. 123-124) afirma que as pessoas iam aos banhos públicos para verem e serem vistas e que "as mulheres que frequentavam assiduamente os banhos mistos possuíam má reputação".

${ }^{23}$ Segundo Brown (2009, p. 221), não devemos nos surpreender com a indiferença dos romanos em relação à nudez. 0 autor menciona que, na sociedade greco-romana, "o papel essencial dos banhos públicos como pontos de reunião da vida cívica faz da nudez entre os pares e diante dos inferiores uma experiência cotidiana inevitável".
} 
seguidas firmemente, numa tentativa de dominar e disciplinar o seu corpo. Nesse sentido, nos são valiosas as as reflexões de Michel de Foucault (2011) sobre a imposição, em nível discursivo e social, de um poder masculino sobre o feminino. Podemos afirmar, então, que mediante o uso de uma linguagem metafórica e persuasiva em seu discurso, Cipriano tentava controlar e disciplinar o corpo da virgem, uma vez que, segundo Pierre Bourdieu (2012), o corpo é a materialização da dominação, exprimindo desigualdades e hierarquias.

A intenção de Cipriano é a dominação desse indivíduo - a virgem -, uma vez que a disciplina é algo que produz, por meio da coerção, uma dominação intensa sobre o outro e contribui para a fabricação de seu corpo (FOUCAULT, 2011; RODRIGUES, 2006). Segundo Foucault (2011, p. 155), por meio da coerção, o indivíduo é levado a um aperfeiçoamento e a uma qualificação e, no caso das virgens cristãs, o exercício cada vez mais rigoroso da disciplina levaria à perfeição do corpo, à supressão de uma "natureza feminina débil" e a um crescimento espiritual. De tal forma, Cipriano, como representante e porta-voz da Igreja, contribui para a formação de uma consciência que perpetua os princípios de uma sociedade patriarcal como era a greco-romana e colabora para a conservação das identidades de gênero. ${ }^{24}$

Em suma, em seu tratado, Cipriano traça o ideal de virgem cristã e a importância delas para a Igreja que estava se institucionalizando. Nele, podemos averiguar quais eram as normas e as regras que as virgens deveriam seguir, o que deveriam usar e portar, quais os lugares que poderiam frequentar, com quem poderiam se relacionar e as funções que deveriam desempenhar.

Todas essas proibições, normas e censuras que encontramos no De habitu uirginum entram no cômputo de Cipriano para justificar que uma virgem somente pode ser considerada sponsa Christi se se comporta de acordo com as regras impostas. A esposa de Cristo, então, deve possuir um comportamento digno: recatada, humilde, obediente, que segue a disciplina eclesiástica e as normas estabelecidas pelo bispo.

Cremos que ao empregar a expressão da sponsa Christi, Cipriano justifica o seu empenho em disciplinar a virgem, ou melhor, o corpo e a sexualidade da virgem. Portanto, segundo Cipriano, se o desejo das virgens cristãs - e, de forma geral, de todas as mulheres cristãs - for o de serem fiéis à doutrina estabelecida, elas devem renunciar a qualquer tipo de ornamento e rejeitar o cuidado com o corpo. Caso isso não fosse feito, o bispo garantiria que ela fosse culpabilizada, desprezada e, consequentemente,

\footnotetext{
${ }^{24}$ Nesse sentido, concordamos com Joan Scott (1995, p. 75), que define gênero como "uma categoria social imposta sobre um corpo sexuado". De tal forma, esse conceito é compreendido como uma construção, o que indica a rejeição de explicações a partir do determinismo biológico contido no uso dos termos sexo ou diferença sexual. A diferença, então, estabelecida entre homens e mulheres é uma criação social, bem como a formulação de "papéis adequados" atribuídos a ambos.
} 
condenada. De tal modo, Cipriano considera as virgens adúlteras quando não atuam de acordo com a disciplina e se adornam, sendo, portanto, consideradas corruptas, reiterando que esse tipo de comportamento é repreensível. Para o bispo, a virgem que não possui o comportamento apropriado pode se transformar em adúltera, não em relação ao seu marido, mas a Cristo (non mariti sed Christi adulterae).

\section{Considerações finais}

A abstinência sexual permanente foi predicada pelos autores cristãos como a condição mais perfeita do corpo humano e mais próxima da divindade de Cristo. Ela se mostrou como uma decisão autônoma da mulher e se associou ao resgate do seu corpo de uma possível sexualidade não desejada (HIDALGO DE VEGA, 1991). Os autores cristãos apresentavam a vida de castidade permanente como um estado de superioridade em relação à situação matrimonial e tratavam de convencer as mulheres das vantagens em se tornar uma virgem, qual seja, a emancipação em relação à autoridade masculina, subtraindo-se da escravidão do casamento, de uma reprodução forçada e do cuidado dos filhos e do marido.

Todo o discurso teórico dos autores cristãos, incluído Cipriano, que ao nível conceitual e especulativo, apresentava a opção da castidade como um ato emancipatório e libertador para a mulher, tem sua justificação e explicação no fato de que a superioridade desta condição faria as mulheres semelhantes aos anjos de Deus, e que elas se legitimariam com a completa dedicação a Deus, transformando-se em esposas de Cristo. Este ato, a princípio, libertador, encerrou-se neste patamar, pois, dentro da Igreja hierarquizada, "sob a autoridade do bispo, dispensador da palavra e dos sacramentos, assistido pelos padres e pelos diáconos" (ALEXANDRE, 1990, p. 536), a função da mulher ficou sempre submetida a dos homens.

Assim, quando se acentuaram os aspectos sacerdotais e a distinção clero-laica na Igreja, as mulheres receberam um lugar limitado. Não foi permitido às mulheres ocuparem as mesmas posições sacerdotais que os homens ocuparam dentro da instituição cristã oficial. A elas não foi permitido evangelizar, batizar, ensinar e administrar os sacramentos. Assim, o discurso sobre autonomia e liberdade, que estava atrelado à castidade, era contraditório com a real atividade e a função que as mulheres desempenharam na Igreja. A organização das funções sacerdotais das mulheres ficou submetida à dos homens, seguindo, assim, a ordem da sociedade romana. De forma mais ou menos sutil, porém contundente, a Igreja conseguiu o silêncio das mulheres e a sua cabeça coberta com o véu 
em sinal de submissão. Essa marginalização das mulheres foi legitimada doutrinalmente com o mito de Eva, a maldição de Gênesis e as proibições paulinas. ${ }^{25}$

Não houve, então, uma participação igualitária da mulher dentro da Igreja. A mulher foi confinada a atividades subalternas e submetida à autoridade masculina, própria de sua natureza inferior, segundo o discurso misógino que prevalecia à época. O ideal místico de mulher cristã se desdobrou em quatro protótipos, que agrupavam todas as mulheres cristãs suscetíveis de uma valorização positiva, porém subalterna às lideranças masculinas: a virgem, a viúva, a mãe e a diaconisa. A virgem foi o modelo primeiro de mulher cristã e era valorizada por sua devoção voluntária a uma abstinência sexual perpétua. No cristianismo primitivo, a castidade das virgens cristãs desempenhou um papel libertador e emancipador para ela, na medida em que se colocou como um ataque direto aos objetivos clássicos da cidade antiga: casamento e procriação.

A abstinência sexual, entendida em sentido lato como a supressão do corpo, mostrou-se como o meio pelo qual os cristãos foram capazes de mudar seu corpo. A castidade e a consequente renúncia ao matrimônio e à maternidade tiveram para a mulher uma dimensão que foi além da consideração da virgindade como modelo de vida a seguir. Ela expressou a possibilidade de dispor livremente do seu corpo e de escolher uma forma de vida à margem dos padrões socioculturais que a sociedade greco-romana pagã oferecia como algo obrigatório (HIDALGO DE LA VEGA, 1993, p. 230-232).

Apesar de a abstinência sexual ter se mostrado como uma decisão autônoma da mulher, pelo resgate do seu corpo a uma sexualidade não desejada - casamento e procriação -, as autoridades eclesiásticas (bispos, presbíteros, diáconos, etc.) continuaram a ter o controle sobre o corpo das mulheres; se não era obrigando-as ao casamento, como fazia o paterfamilia, e a ter filhos, como era esperado no matrimonio, era determinando o que elas poderiam ou não utilizar como indumentária e os espaços que poderiam ou não frequentar, como pudemos ver na obra de Cipriano de Cartago.

\footnotetext{
${ }^{25}$ As passagens bíblicas referenciadas mencionam o seguinte: "Deus disse à mulher: 'Multiplicarei as dores de tuas gravidezes, na dor darás à luz filhos. Teu desejo te impelirá ao teu marido e ele te dominará'" (Gênesis 3, 16); "Quero, porém, que saibas: a origem de todo homem é Cristo, a cabeça da mulher é o homem, e a cabeça de Cristo é Deus" (Coríntios 1, 11, 3); "Estejam caladas as mulheres nas assembleias, pois não lhes é permitido tomar a palavra. Devem ficar submissas, como diz a Lei. Se desejam instruir-se sobre algum ponto, interroguem os maridos em casa; não é conveniente que a mulher fale nas assembleias" (Coríntios 14, 34-35); "Durante a instrução a mulher conserve o silêncio, com toda submissão. Não permito que a mulher ensine ou domine o homem. Que conserve, pois, o silêncio. Porque primeiro foi criado Adão, depois Eva. E não foi Adão que foi seduzido, mas a mulher que, seduzida, caiu em transgressão. Entretanto, ela será salva pela sua maternidade, desde que, com modéstia, permaneça na fé, no amor e na santidade" (Timóteo 2, 11-15).
} 


\section{Referências}

\section{Documentação textual}

BÍBLIA DE JERUSALÉM. São Paulo: Paulus, 2002.

CIPRIANO DE CARTAGO. Obras de San Cipriano, Tratados, Cartas. Introducción, versión y notas de Julio Campos. Madrid: BAC, 1964.

CIPRIANO DE CARTAGO. Obras completas. São Paulo: Paulus, 2016. v. 35/1.

\section{Obras de apoio}

ALEXANDRE, M. Do anúncio do Reino à Igreja: papéis, ministérios, poderes femininos. In: PERROT, M.; DUBY, G. (Ed.) História das mulheres no Ocidente: a Antiguidade. Porto: Afrontamento, 1990, p. 511-563. v. 1.

ASPEGREN, K. The male woman: a feminine ideal in the Early Church. Michigan: Acta Universitatis Upsaliensis, 1990.

BOURDIEU, P. A dominação masculina. Rio de Janeiro: Bertrand Brasil, 2012.

BROWN, P. Antiguidade Tardia. In: VEYNE, P. (Org.). História da vida privada: do Império Romano ao Ano Mil. São Paulo: Companhia das Letras, 2009, p. 213-284. v. 1.

BROWN, P. Corpo e sociedade: o homem, a mulher e a renúncia sexual no início do cristianismo. Rio de Janeiro: Zahar, 1990.

CAMPOS, J. Introducción. In: CIPRIANO DE CARTAGO. Cartas e tratados. Madrid: BAC, 1964 , p. $5-134$

CANTARELLA, E. La calamidad ambigua: condición e imagen de la mujer en la Antigüedad griega y romana. Madrid: Clásicas, 1991.

CHEVITARESE, A. L.; CORNELLI, G. Judaísmo, cristianismo e helenismo: ensaios acerca das interações culturais no Mediterrâneo antigo. São Paulo: Annablume, 2007.

DE CERTEAU, M. A invenção do cotidiano: artes de fazer. Petrópolis: Vozes, 2009.

DELL'OSSO, C. Cipriano vescovo di Cartagine: lettere 1-50. Roma: Cittá Nuova, 2006.

DUNN, G. D. Cyprian and women in time of persecution. Journal of Ecclesiastical History, n. 4, p. 205-225, 2005a.

DUNN, G. D. Infected sheep and diseased cattle, or the pure and holy flock: Cyprian's pastoral care of virgins. Journal of Early Christian Studies, v. 11, n. 1, p. 1-20, 2003.

DUNN, G. D. Widows and other women in the pastoral ministry of Cyprian of Carthage. Augustinianum, n. 45, p. 295-307, 2005b. 
FIORENZA, E. S. In memory of her: a feminist theological reconstruction of Christians origins. New York: Crossroad, 1994.

FOUCAULT, M. Vigiar e punir. Rio de Janeiro: Graal, 2011.

GRAÇA, I. Marcial e os banhos em Roma. Humanitas, n. 56, p. 117-136, 2004.

GRIMAL, P. A vida em Roma na Antiguidade. Lisboa: Europa-América, 1995.

GRIMAL, P. Vierges et virginité. In: TORDJAMN, G. (Éd). La prémiere fois ou le roman de la virginité perdue à travers les siécles et les continents. Paris: Ramsay, 1981.

HIDALGO DE LA VEGA, M. J. Mujeres, carisma y castidade en el cristianismo primitivo. Gerión, n. 11, p. 229-244, 1993.

HIDALGO DE VEGA, M. J. Usos sexuales y amorosos de las mujeres en el mundo romano: imagen o realidad? In: BLÁZQUEZ PÉREZ, C.; ALVAR, J.; WAGNER, C. G. (Coord.). Sexo, muerte y religión en el Mundo Clássico. Cáceres: ARYS, 1991, p. 99-110.

HOPKINS, K. On the probable age structure of the Roman population. Population Studies, v. 20, n. 2, p. 245-264, 1966.

KEENAN, S. A. E. Saint Cyprian, treatises. New York: The Catholic University of America Press, 1958.

MARTíNEZ LÓPEZ, C. La virginidad em las jóvenes de la Antigua Roma. Arenal, v.1, n. 2, p. 169-184, 1994.

MENTXACA, R. Notes about the wives of Christ (Sponsae Christi) and the married women in the De habitu uirginum of Cyprian of Carthage. Raudem, v.1, p. 8-30, 2013.

MENTXAKA, R Cipriano de Cartago y las vírgenes consagradas. Observaciones históricojurídicas a la carta cuarta de sus epistulae. Lecce: Grifo, 2010.

PAGELS, E. Adão, Eva e a serpente. Rio de Janeiro: Rocco, 1992.

PAGELS, E. H. Paul and women: a response to recent discussion. Journal of the American Academy of Religion, v. 42, n. 3, p. 538-549, 1974.

POMEROY, S. B. Diosas, rameras, esposas y esclavas: mujeres en la Antigüedad Clásica. Madrid: Akal, 1999.

RAMIS, G. La consagración de la mujer en las liturgias occidentales. Roma: Edizioni Liturgiche, 1990.

ROBERT, J. N. Os prazeres em Roma. São Paulo: Martins Fontes, 1995.

RODRIGUES, J.C. Tabu do corpo. Rio de Janeiro: Fiocruz, 2006.

ROUSSELLE, A. Porneia: sexualidade e amor no Mundo Antigo. São Paulo: Brasiliense, 1984.

SCOTT, J. Gênero: uma categoria útil de análise histórica. Educação e Realidade, v. 20, n. 2, p. 71-99, 1995. 
SCROGGS, R. Paul and the eschatological woman. Journal of the American Academy of Religion, v. 40, n. 3, p. 283-303, 1972.

SOARES, C. da S. Cipriano de Cartago e os semi-cristãos: um bispo em alerta contra os perigos da cidade. In: VENTURA DA SILVA, G.; MORAIS DA SILVA, E. C.; LIMA NETO, B. M. (Org.). Espaços do sagrado na cidade antiga. Vitória: GM, 2017, p. 65-78.

SOARES, C. da S. Cipriano e o tratado De habitu uirginum: a construção de fronteiras entre as virgens cristãs e a busca pela pureza na igreja de Cartago (século III d.C.). Romanitas, n. 1, p. 38-53, 2013.

SOARES, C. da. S. Entre o ideal de conversão e a conversão "artificial": fronteiras fluidas entre cristãos, judeus e pagãos na obra de Cipriano de Cartago (século III d.C.). Romanitas, n. 3, p. 129-152, 2014.

TORRES, J. Misoginia en la literatura patrística: hacia una sistematización tipológica del ideal feminino. In: POMER, J. J.; REDONDO, J.; TORNÉ, R. (Ed.). Misogínia, religió i pensament a la literatura del món antic i la seua recepció. Amsterdam: Adolf M. Hakkert, 2013, p. 243-271.

VICIANO, A. El papel de la mujer en la teología de Cipriano de Cartago. Antigüedad y Cristianismo, v. XXIII, p. 569-580, 2006.

VIZMANOS, F. de S. J. Las vírgenes cristianas de la Iglesia primitiva. Madrid: BAC, 2009.

WALKER, W. O. 1 Corinthians 11:2-16 and Paul's views regarding women. Journal of Biblical Literature, v. 94, n. 1, p. 94-110, 1975.

WARD, R. B. Women in Roman baths. The Harvard Theological Review, v. 85, n. 2, p. 125-147, 1992.

WATSON, E. W. The De habitu virginum of St. Cyprian. Journal of Theological Studies, n. 22, p. 361-367, 1920-1921.

ZAIDMAN, B. L. As filhas de Pandora: mulheres e rituais nas cidades In: PERROT, M.; DUBY, G. (Ed.). História das mulheres no Ocidente: a Antiguidade. Porto: Afrontamento, 1990, 411-463. v. 1. 